\title{
Tolerability and cell yield from nasal biopsies obtained in the outpatient setting
}

UNIVERSITY OF CAMBRIDGE
Mark McClure ${ }^{1}$, Lucy A. Truman ${ }^{2}$, Marcos Martinez Del Pero ${ }^{2}$, David Jayne ${ }^{1}$, Rachel Jones ${ }^{1}$

${ }^{1}$ Department of Medicine, Addenbrookes Hospital, Cambridge, UK

2 ENT Department, Addenbrookes Hospital, Cambridge, UK

\section{Background}

Granulomatosis with polyangiitis (GPA), a subtype of the anti-neutrophil cytoplasmic antibody (ANCA) - associated vasculitis (AAV), is characterised by pauci-immune necrotising small-vessel vasculitis and glomerulonephritis, combined with granulomatous inflammation, particularly in the lungs and upper airways. Over $70 \%$ of patients with GPA have ENT involvement at presentation with a prevalence of $90 \%$ on follow up. This frequently involves granulomatous inflammation of the nasal mucosa, which is easily accessible for biopsy. Unfortunately, diagnostic yield is poor and large samples taken under general anaesthetic are usually required.

The B cell depleting monoclonal antibody, rituximab is an effective treatment option for GPA. Peripheral B cell depletion is observed following rituximab, however there is frequently incomplete B cell depletion at the tissue level. Assessment of lymphocyte subsets in the tissue following rituximab may help predict relapse and guide treatment.

We aimed to develop a minimally invasive nasal biopsy technique that could be performed under local anaesthetic in the outpatient setting.

\section{Patients and Methods}

Patients with active GPA define as 1 major or 3 minor BVAS/WG items were eligible for the study. Biopsies were performed prior to commencement of remission induction treatment with either rituximab or cyclophosphamide.

A mixture of Lidocaine hydrochloride $5 \%$ and phenylephrine $0.5 \%$ was applied topically. Biopsies were taken from the area of inflammation, the post-nasal space (PNS), the lateral wall and septum using cupped forceps (maximum spread $5 \mathrm{~mm}$ ) under direct vision with a nasoendoscope. A biopsy comprising full thickness of the epithelial layer to a minimum diameter of $2 \mathrm{~mm}$ was acceptable.

Cells were dissociated from the tissue using a liberase and DNAse digestion step and passed through a $70 \mathrm{~nm}$ cell strainer to produce a single cell solution. Fluorescently labelled antibodies were added to the solution which was then run on an LSR-Fortessa flow cytometer enabling accurate immunophenotyping of lymphocytes

\section{Results}

\section{Tolerability}

Of the 7 patients who underwent nasal biopsy under LA, 5 reported either no or mild discomfort. One patient reported severe discomfort that was attributed to an insufficient level of anaesthetic and would not be willing to have another biopsy. Reassuringly, 6 patients said they were willing to have a repeat biopsy.

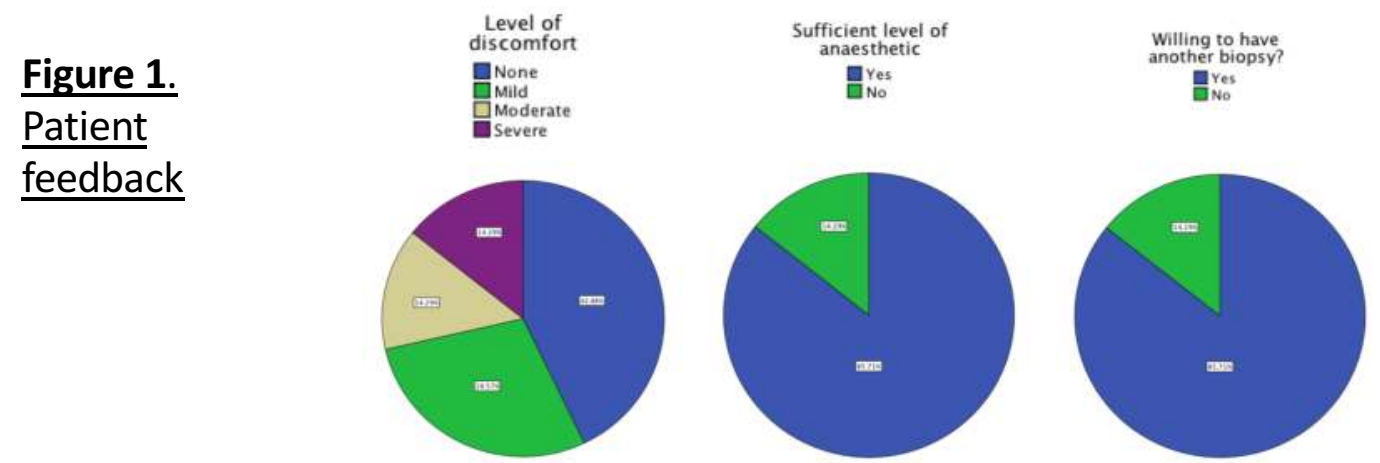

\section{Complications}

There were no major and 2 minor complications. One episode of bleeding required local cautery.

\section{Optimal biopsy site}

Cell yields (total CD19+ and CD3+ cells) were highest from the PNS biopsy site (median 38355, IQR 1002-97185) compared with the lateral wall (1136, IQR 202-2596), septum (236, IQR 175-1030) and inflamed area (197, IQR 72-397). Despite the superior cell yields from the PNS, significant variation between samples was observed. 4 samples had enough cells for adequate immunophenotyping

Figure 2. Total CD4+ and CD19+ cells

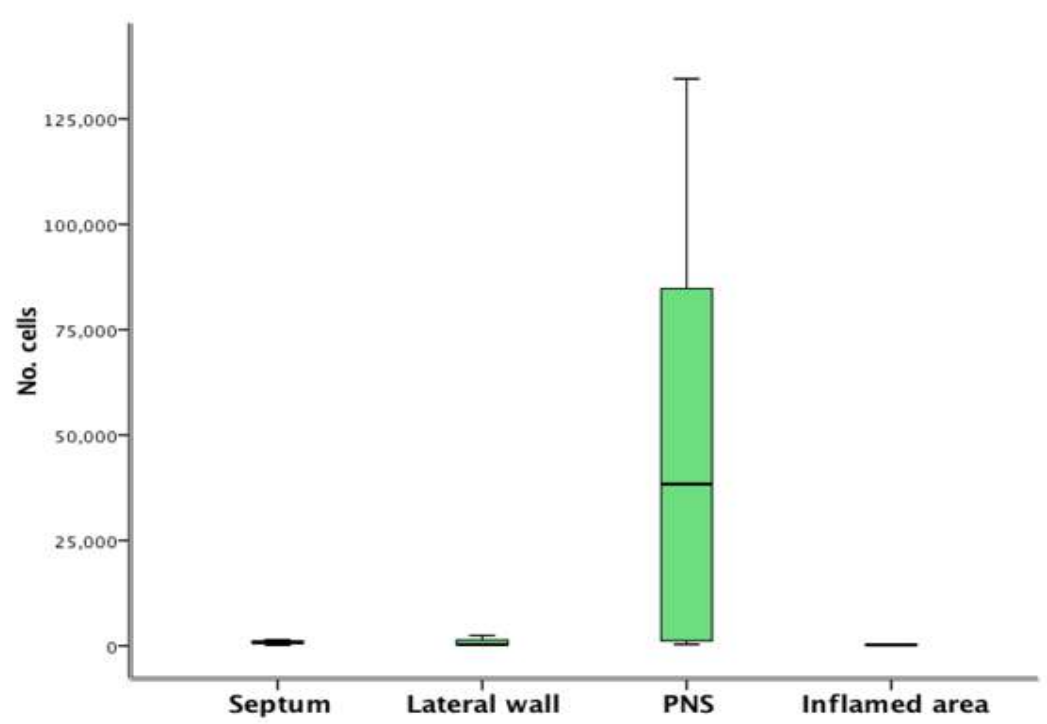

Table 1. Disease and treatment variables

Variable Value (range)

N

ANCA subtype

BVAS/WG (mean) 6 PR3, 1 MPO

Sino-nasal disease present ANCA titre

CRP

Prednisolone dose, $\mathrm{mg}$

IV steroid given prior to biopsy

$2 / 7$

Previous rituximab

2/7

Background oral immunosuppressive agent

$0 / 7$

\section{B cell subsets from the PNS}

CD3+CD4+ cells (81\%) were the dominant $T$ cell and CD19+C27+lgD- memory $(68 \%)$ the most frequent $B$ cells. The predominance of memory $B$ cells suggests sampling of lymphoid tissue, which is unsurprising given the proximity to the adenoids Figure 3 . B cell subsets from the PNS

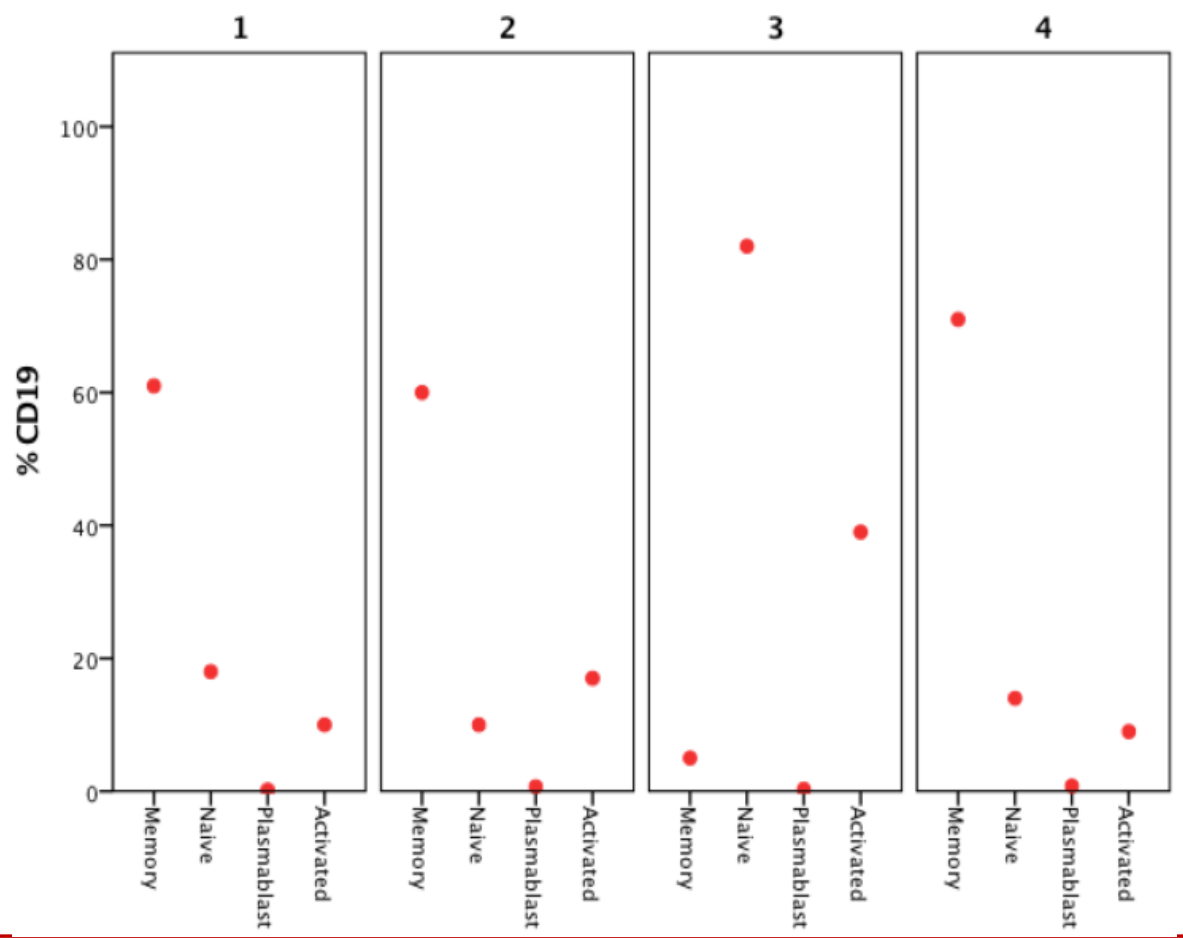

\section{Conclusions}

Nasal biopsy taken under local anaesthetic in the outpatients setting was safe and well tolerated. The PNS was the optimal biopsy site but sample quality was variable. Cell yields were high enough to accurately examine lymphocyte subsets. This technique may be used in future studies to assess the effects of B cell depletion therapy at the tissue level.

\section{References}

1. Alberici, F. and Jayne, D. R. W. (2013) 'Impact of rituximab trials on the treatment of ANCA-associated vasculitis', Nephrol Dial Transplant, 0, pp. 1-12. doi: 10.1093/ndt/gft318.

2. Borner, U., Landis, B. N., Banz, Y., Villiger, P., Ballinari, P., Caversaccio, M. and Dubach, P. (2012) 'Diagnostic value of biopsies in identifying cytoplasmic antineutrophil cytoplasmic antibody-negative localized Wegener's granulomatosis presenting

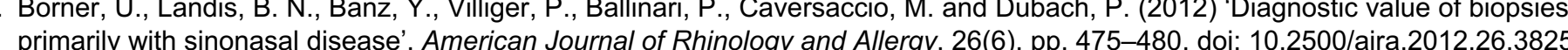

3. Del Buono, E. A. and Flint, A. (1991) 'Diagnostic usefulness of nasal biopsy in Wegener's granulomatosis.', Human pathology, 22(2), pp. 107-10. Available at: http:///www.ncbi.nlm.nih. gov/pubmed/2001873 (Accessed: 7 March 2017).
4. Christiaan Hagen, E., Daha, M. R., Hermans, J., Andrassy, K.. Csernok, E., Gaskin, G., Lesavre, P., Ldemann, J., Rasmussen, N., Alberto Sinico, R. Wiik, A. and Van Der Woude, F. J. (1998) 'Diagnostic value of standardized assays for antineutrophil cytoplasmic antibodies in idiopathic systemic vasculitis for the EC/BCR project for ANCA assay standardisation', Kidney international, 53, pp. 743-753. doi: 10.1046/j.1523-1755.1998.00807 